\title{
THE IMPACT OF RELINING BAR-IMPLANT RETAINED OVERDENTURE ON ALVEOLAR BONE RESORPTION IN POSTERIOR MANDIBLE: A 5-YEARS RETROSPECTIVE STUDY
}

\author{
Ahmed Samir Khair Allah* and Mohammed Omran Hamed ${ }^{* *}$
}

\begin{abstract}
Purpose. The purpose of this study was to evaluate the effect of relining of mandibular implant retained overdenture with resilient liner on posterior mandibular ridge resorption.

Material and methods. Twelve completely edentulous patients received 2 implants in the canine area of the mandible and connected with a Dolder bar. Patients were randomly divided in two groups: Group I (non-relined group), patients received bar/clip attachment and acrylic mandibular overdenture without relining. Group II (relined group), patient received bar attachment and acrylic mandibular overdenture totally relined with soft liner (around the bar and the distal extensions of the denture). Proportional measurements in terms of posterior area index (PAI) of the residual ridges were measured on panoramic images of Cone Beam computerized tomography taken after the overdenture insertion (base line, T0) and five years after the overdenture insertion (T5).
\end{abstract}

Results. Group I demonstrated statistically significant higher mean change in PAI (bone loss) compared to group II. The amount of bone loss was $1.23 \mathrm{~mm}$ (in group I) and $.74 \mathrm{~mm}$ (in group II) for each $1 \mathrm{~mm}$ of the residual ridge length. Only group, mandibular bone height, and relining frequencies had a significant correlation with the change in PAI. No significant correlation between age or gender with change in PAI.

Conclusions: Within the limitations of this study, it could be concluded that relined implant retained mandibular overdentures with silicon soft liner over bar attachments is preferred on long term as it reduced posterior mandibular ridge resorption compared to unrelined overdentures.

* Associate Professor of Removable Prosthodontics, Faculty of Dentistry Mansoura University

** Instructor of Oral and Maxillofacial Surgery, Faculty of Dentistry Beni-Suef University 


\section{INTRODUCTION}

Implant-retained overdentures stabilized by 2 implants in the mandibular edentulous ridges are considered the minimum standard of care for edentulous patient due to increased retention and stability, increased patient satisfaction, simplicity and cost effectiveness ${ }^{1}$. Naturally, for the treatment to be justified, it must be seen to be successful over an extended period of time ${ }^{2}$. However, such overdentures were reported to be associated with increasing alveolar ridge resorption over time compared with conventional dentures and implantsupported fixed prostheses due to increased bite forces on posterior mandibular ridges ${ }^{3}$. The implantretained tissue-borne overdenture is dependent on soft tissue support. The anterior part of a mandibular hinging denture is fixed on the 2 implants; while the posterior part of the denture is extended and cantilevered from implants ${ }^{4}$. One of unavoidable longer-term complication associated with hinging implant retained mandibular overdenture is posterior mandibular alveolar bone loss due to free overdenture rotation during function which increase occlusal loading on posterior ridges ${ }^{5,6}$. A better understanding of ridge resorption might allow a better maintenance of two implant-supported overdentures, especially with focus on the frequency of relining and the wear of the attachments. ${ }^{6}$

Different anchor systems may be used for these overdentures and are categorized as splinted or unsplinted. Splinting (bar) attachments have several merits as load and stress sharing between implants ${ }^{7}$, resistance to lateral loads $^{8}$, improved denture stability $^{9}$, and reduction of micromotion at the bone-implant interface especially with immediately loaded implants. ${ }^{10}$ Moreover bar attachments can be used with non-parallel implants, has greater retention and fewer prosthetic complications than other attachments ${ }^{7}$. However, the bar design should be resilient to avoid increased load transmission to the implants. The bar also should be designed to be parallel to the hinge axis to permit free overdenture rotation during function which may result in increased posterior loading ${ }^{3,11,12}$, thereby contributing to increased resorption of the posterior ridge which reaches two to three times that of conventional complete denture wearers ${ }^{3}$

The use of Soft liner as a means of retention to the bar attachments instead of clips was reported in several investigations ${ }^{5,13-20}$. The Soft liner as an attachment provides several merits such as reduced wear, patient comfort, cushioning of masticatory forces to the implants ${ }^{18,19}$. Moreover, they fill spaces in the denture around the bar, thus promoting favourable clinical and radiographic tissue response around implants ${ }^{16}$, increase patient satisfaction ${ }^{13}$, and minimize prosthetic complications compared to clips ${ }^{13}$. Moreover, maxillary ridge resorption and complications were reduced with soft liner attachments of mandibular bar retained overdentures ${ }^{14}$. Evidence exists to suggest that the use of soft lining materials will have a beneficial effect on alveolar bone resorption $^{21,22}$. Babu et al..$^{23}$ reported that soft denture liners significantly reduces the residual ridge resorption in complete denture wearers as compared to conventional denture wearers without denture liner. Unfortunately, conclusive long-term studies on the effect of permanent resilient denture liners on alveolar bone resorptions in patients with implant retained overdentures are still limited. Accordingly, the purpose of this study was to investigate whether or not relining implant retained overdenture will affect alveolar bone resorption in posterior mandible compared to un-relined dentures. The null hypothesis was that there will be no difference in ridge resorption between relined and relined overdentures.

\section{MATERIALS AND METHODS}

\section{Patient cohort and study design}

Twelve edentulous patients (6 males and 6 females, mean age 59 years) regular were selected from outpatient clinic of the prosthodontic department. The inclusion criteria of all participants include; 1) adequate bone volume regarding height and width in the interforaminal area of the mandible 
to receive dental implants of at least $11 \mathrm{~mm}$ in length and $3.7 \mathrm{~mm}$ in diameter. This was checked by Cone Beam computerized tomography made before surgery, 2) adequate restorative space to accommodate the bar attachments (at least $15 \mathrm{~mm}$ (class I) according to Ahuja and Cagna 24,3) all patients complained from insufficient retention of their mandibular denture and need a more stable prosthesis. Exclusion criteria include; patients with chemotherapy or radiotherapy in the last 2 years, patients with bone metabolic disorders such as diabetes mellitus, patients with bleeding disorders, uncooperative patients, and heavy smokers (>10 cigarettes/day). The included patients were informed by treatment protocol and objectives before obtaining informed consents. The protocol of the study was reviewed and approved by the Faculty of dentistry Bani-suef university research Ethics committee (Approved number Approval number: \#FDBSUREC/08042021/KA.

The patients were categorized in blocks according to age, gender, and mandibular bone height, then they were randomly assigned into two groups ( $n=6$ in each group) using balanced random method which ensure that there is no difference in patient characteristics (age, gender, and mandibular bone height) at the beginning of the study. Group I (non-relined group), includes six participants who received two implants connected by bar/clip attachment and acrylic mandibular overdenture without relining. Group II (relined group), includes six participants who received two implants connected by bar attachment and acrylic mandibular overdenture totally relined with soft liner (around the bar and in the distal extensions of the denture).

\section{Surgical and prosthetic procedures}

The existing mandibular denture was duplicated into clear heat cure acrylic resin with radiopaque markers attached to proposed implant sites (at canine areas) to be used as radiographic stent. Cone Beam computerized tomography (CAT Vision ${ }^{\circledR}$, PA, USA) was performed to detect proper implant length and width. The radiographic guide was then converted to surgical guide by attaching metal tubes at canine areas. A crestal incision was made from premolar areas on one side to premolar areas on the other side and full-thickness mucoperiosteal flap was raised. For any sharp knife edge ridges, bone recontouring was performed using a crestal cutter to provide at least one millimeter of bone labial and lingual to the implants. Two implants (TioLogic, Dentaurum) were inserted by the same oral surgeon in the canine areas using two-stage surgical approach. The mucoperiosteal flap was closed using interrupted sutures. The mandibular dentures were relined using tissue conditioner and the occlusion was adjusted. The postoperative medications include antibiotics (Augmentin ${ }^{\circledR}$ 1gm), analgesics, (Ketolac 10mg), anti-inflammatory (Prednisone), and Chlorhexidine digluconate $0.2 \%$ continued for 7 days after surgery. After 3 months, as second stage surgery was performed to expose the implants and healing abutments were connected. After additional two weeks, open tray impression procedure was started. Preliminary maxillary and mandibular impressions were performed to obtain primary casts on which custom trays were made. Mandibular tray was constructed with two openings in the canine area. After border molding, the final impressions were taken using medium body rubber base impression material (polyether, Impregum Penta). The impression material was removed from the opening of the three using sharp scalpel. The long impression posts were connected to the implants and splinted with Duralay acrylic resin to prevent movements that might occur during impression removal. Light body impression (Speedex, Coltene) was injected around the posts, and autopolymerized acrylic resin was used to secure the posts to the polished surface of the tray. The impression was removed, implant analogues were connected to the posts in the impression was poured using dental stone. Bar abutments were threaded to the implant analogues and plastic resin of Dolder resilient bar (TioLogic, Dentaurum) was luted to the plastic 
bar abutments. 1-1.5mm space under the bar was maintained for oral hygiene purposes (Fig 1). The bar was invested and cast in cobalt-chromium alloy. The cast bar was tried in for passive fit in patient mouth. Recorded blocks were then constructed and used to record jaw relations. Balancing occlusal scheme using semi-anatomic acrylic teeth was used. Try in for aesthetics and occlusion was completed.

For group I (unrelined overdentures, control) U-shaped titanium clips (Bar rider rematitanR, height $3 \mathrm{~mm}$ ) were placed over the bar. The retention tags were welded to the clips to retain the clips in the acrylic resin of the denture base. Packing of acrylic resin and denture processing was made in the usual manner (fig 2a). For group II (relined dentures), the space under the bar was blocked with stone on the master cast. A silicone-based heat-cure Softliner material (Molloplast-B soft denture liner, DETAX, Ettlingen-Germany), was adapted over the bar and the residual ridge (thickness of the soft liner should be at least $2-3 \mathrm{~mm}$ to retain viscoelastic properties and resiliency) ${ }^{25}$. Then packing of acrylic resin over the Soft liner was performed and denture processing was made in the usual manner. The Soft liner was used as a means of retention to the bar instead of clips $^{5,13-20}$ and at the same time used as a relining for the fitting surface of the mandibular overdentures (fig 2b). Overdentures were delivered to the patients,and any necessary adjustment of denture borders and occlusion was made and oral hygiene instructions were given. Regular recalls were scheduled every 6 months to replace soft liner

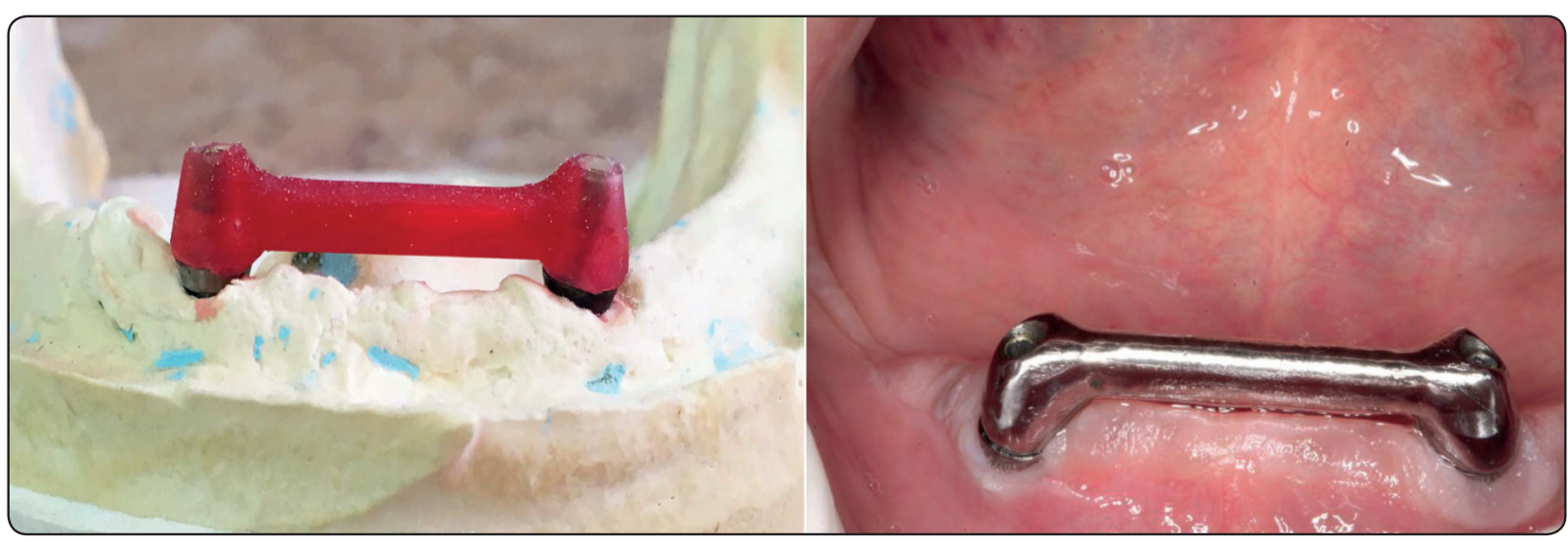

Fig. (1) Dolder bar joint connected to the implants intraorally

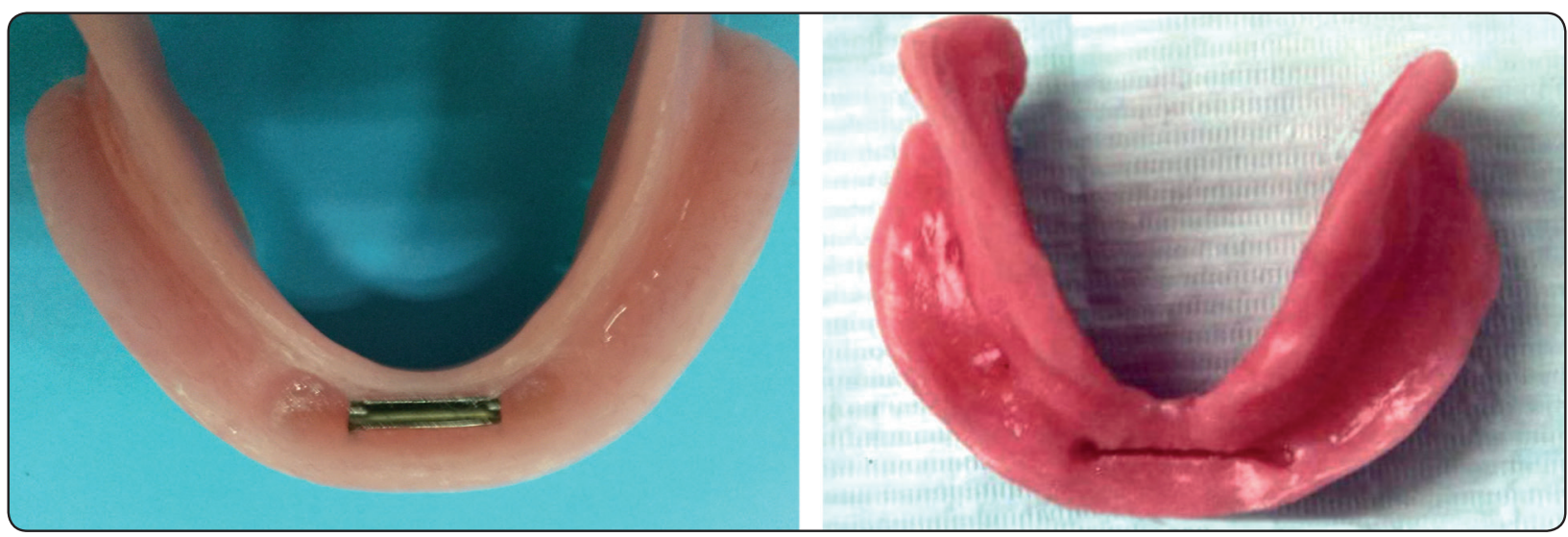

Fig. (2) Group I (unrelined overdentures, metal clip attachment, control), group II (relined overdentures, soft liner attachment, study group) 
if loss of resiliency or separation from the denture base occurs, to repair denture base if fracture occurs and to restore occlusion if teeth wear occurs.

\section{Measurements of posterior mandibular alveolar bone resorption}

Bilateral posterior areas of the residual ridges were measured on panoramic images of Cone Beam computerized tomography taken after the overdenture insertion (base line, T0) and five years after the overdenture insertion (T5). The scan was made by the same CBCT machine (CAT Vision $\left.{ }^{\circledR}, \mathrm{PA}, \mathrm{USA}\right)$. The scan parameters were standardized for all participants $(120 \mathrm{kVp}, 5 \mathrm{~mA}$, a voxel size of $0.25 \mathrm{~mm}$, acquisition time of 8.9 seconds, FOV of $8 \mathrm{~cm}$ high and $16 \mathrm{~cm}$ wide, and slice thickness of $0 \mathrm{~mm}$ ). The level and width of the images were standardized. A "curve tool" which bisects the alveolar ridge was used to create panoramic images. The images were saved as DICOM files. Measurement of posterior mandibular ridge resorption was made using proportional measurement originality described by Wilding et al. ${ }^{26}$ who used anatomical land marks on panoramic images to avoid the problems of magnification and distortion. The technique was later modified by using Tuebinger method ${ }^{6}$ which uses not only anatomical structures in the panoramic radiographs, but also implant structures as reference points (defined more clearly than anatomical landmarks and leads to more accuracy).

On the panoramic images of the CBCT, the following landmarks were determined (fig 3); 1) AS; a line perpendicular from sigmoid notch (S) to inferior border of the mandible at point $(\mathrm{A}), \mathrm{AB}$; a line connect point $A$ to the apex of implant (point B), BC; a line form point B (apex of the implant) to point $\mathrm{C}$ (implant platform), $\mathrm{AD}$; a line bisects the angle $\mathrm{SAB}$ and intersect the ridge at point (D). C'D; A line which followed the crest of the alveolar ridge in small straight increments from implant platform to wards point $\mathrm{D}$. This reference points and lines resulting in 2 areas; one area is the reference area which is independent of resorption that might occur $\left(\mathrm{ABCD}\right.$ in $\left.\mathrm{mm}^{2}\right)$, and the other area is experimental area which represents the resorption (ABC'D in $\mathrm{mm}^{2}$ ). Posterior area index (PAI) was calculated as $\mathrm{PAI}=\mathrm{ABC}{ }^{\prime} \mathrm{D} / \mathrm{ABCD}$. PAI for right and left sides of the posterior mandible was averaged. The change in the posterior area index (PAI) (which represent ridge resorption) for each participant was detected by subtracting the PAI at 5 years from the PAI at baseline (after insertion). The estimation of bone resorption in each millimeter along the entire ridge length was calculated by dividing the change in PAI (in $\mathrm{mm}^{2}$ ) by the length of posterior ridge (DC) ${ }^{14,27}$. The tracing and measurements were performed by the same examiner after instruction and calibration

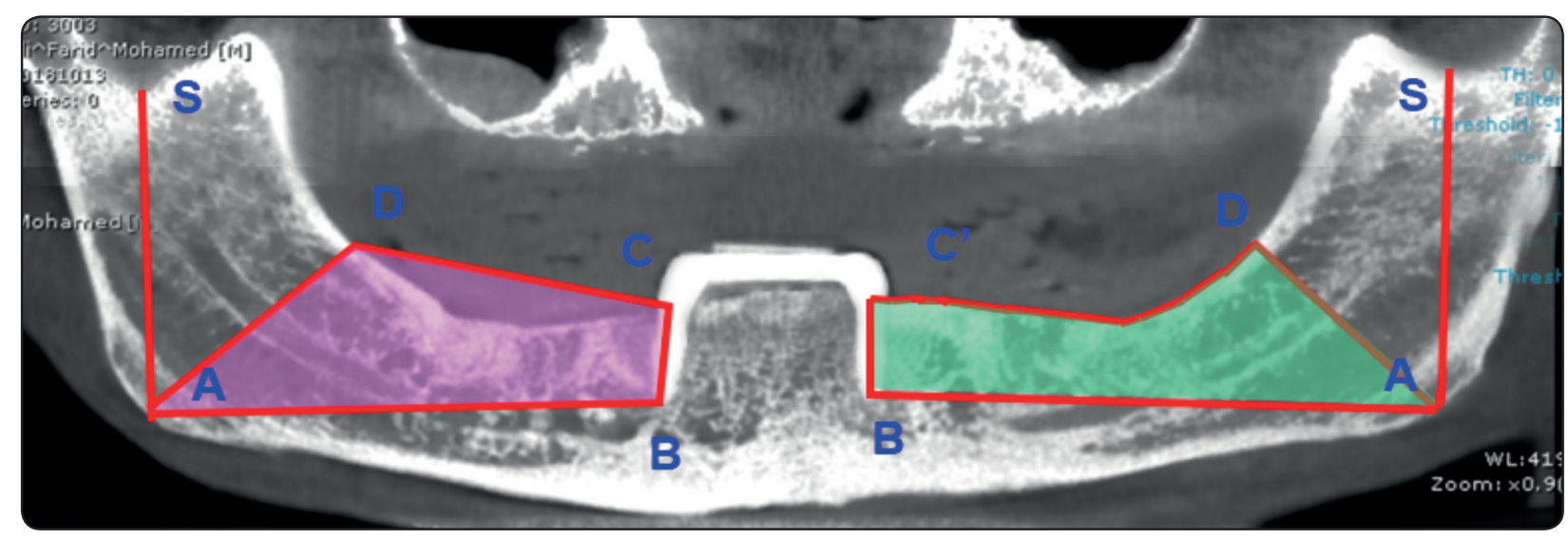

Fig. (3) Traced panoramic image of the CBCT scan; S; sigmoid notch, A; point at which AS line perpendicular to mandibular plane. $\mathrm{B}$; apex of the implant, $\mathrm{C}$; implant platform, $\mathrm{D}$; point at which $\mathrm{AD}$ that bisect $\mathrm{SAB}$ angle meet the crest of the ridge. 


\section{Statistical analysis}

To compare differences in PAI between groups independent samples t-test was used. A linear regression analysis was used to detect any relation between PAI and the following confounders: group, age, gender, initial height of mandibular bone, and relining frequencies. The level of significance was adjusted at 5\% with $95 \%$ confidence interval. The data were analyzed using SPSS $^{\circledR}$ software version 25 (SPSS Inc., Chicago, IL, USA)

\section{RESULTS}

The descriptive statistics of the study population for both groups are shown in (Table 1). Comparing the baseline characteristics of groups demonstrated no significant difference between groups. After 5 years, an attempt was made to recall all patients for radiographic examinations. One patient in group 1 was bed ridden and unable to attend due to advanced age and one patient in group 2 was excluded from the study due to death so the total numbers of patients became ten ( $\mathrm{N}=5$ in each group). The study was conducted according to intentions to treat principal.

Mean change in posterior area index (PAI) between T0, T5 for both groups was shown in (Table 2). The mean change in PAI for un-relined group and the relined group was $0.120 \pm 0.051$ and $0.094 \pm 0.057$ respectively. The change in PAI in unrelined and relined groups was more than .04 (the limit that determined for ridge resorption) $)^{3,26}$. This means that ridge resorption occurs in both groups. Statistical analysis revealed that; un-relined group demonstrated statistically significant higher mean change in PAI compared to relined group $(\mathrm{p}=.002)$, while relined group demonstrated a small but not significant change in PAI after 5 years.

The difference in experimental area (in $\mathrm{mm} 2$ ) between baseline and after 5 years was $49.45 \mathrm{~mm} 2$ and $31.87 \mathrm{~mm} 2$ for un-relined and relined groups respectively. When these values were divided by the length of the residual ridge $(40.1 \mathrm{~mm}$ in un relined group) and $42.7 \mathrm{~mm}$ in relined group, this resulted in $1.23 \mathrm{~mm}$ (group I) and $.74 \mathrm{~mm}$ (group II) bone resorption for each $1 \mathrm{~mm}$ of the residual ridge length.

Regression analysis of the correlation between PAI and the confounding variables (group, age, gender, mandibular bone height and relining times) over 5 years is presented in table 3. Only group, mandibular bone height, and relining frequencies had a significant correlation with the change in PAI. No significant correlation between age or gender with change in PAI. The unrelined group was associated with increase in PAI by $10.6 \%$ per each year compared to relined group $(\mathrm{p}=.004)$. The increase in mandibular bone height by one millimeter was associated with $1.5 \%$ reduction in PAI per year $(\mathrm{P}=.022)$. For each relining time, a reduction in the PAI by $3.2 \%(\mathrm{P}=.040)$ was observed.

TABLE (1) Descriptive statistics of the study population for both groups (at base line)

\begin{tabular}{|l|l|l|l|}
\hline & Age in years & Gender & Mandibular bone height in mm \\
\hline Relined group & $59.4 \pm 4.5$ & 3 males $/ 3$ females & $23 \pm 2.4$ \\
\hline Un-relined group & $57.3 \pm 5.4$ & 3 males $/ 3$ females & $21 \pm 2.9$ \\
\hline t-test/chi-square p value & .365 & 1.00 & .254 \\
\hline
\end{tabular}

*P is significant at $5 \%$ level of significance 
TABLE (2): Mean difference in posterior area index (PAI) over time for each group

\begin{tabular}{|c|c|c|c|c|}
\hline & $\begin{array}{c}\text { Mean change in } \\
\text { PAI }\end{array}$ & Maximum PAI & Minimum PAI & $\begin{array}{c}\text { Ridge height reduction } \\
\text { after 5 years in } \mathbf{~ m m}\end{array}$ \\
\hline Un-relined group $(\mathbf{X} \pm$ SD) & $0.120 \pm 0.051$ & 0.23 & 0.064 & $1.23 \mathrm{~mm}$ \\
\hline Relined group $(\mathbf{X} \pm$ SD) & $0.094 \pm 0.057$ & 0.20 & 0.001 & $0.74 \mathrm{~mm}$ \\
\hline T- test & \multicolumn{3}{|r|}{$* \mathbf{P}=. \mathbf{0 0 2} *$} \\
\hline
\end{tabular}

$X:$ mean, SD: standard deviation, *: Statistically significant difference at 5\% level of significance

TABLE (3) Regression analysis of the correlation between PAI and the confounding variables (group, age, gender, mandibular bone height and relining times) over 5 years

\begin{tabular}{|l|l|l|l|l|c|}
\hline \multicolumn{1}{|c|}{ Confounders } & \multicolumn{1}{c|}{ Co } & \multicolumn{1}{c|}{ St Er } & \multicolumn{1}{c|}{$\boldsymbol{t}$} & \multicolumn{1}{c|}{$\boldsymbol{P}$} & \multicolumn{1}{c|}{ 95\% CI } \\
\hline Group & .106 & .028 & 2.914 & $.004^{*}$ & .040 to 0.162 \\
\hline Age & .002 & .003 & .538 & .567 & -.025 to -0.004 \\
\hline Gender & .004 & .005 & .654 & .789 & -.026 to -0.005 \\
\hline Bone height & -.015 & .006 & -2.817 & $.022^{*}$ & -.109 to 0.018 \\
\hline Relining times & .032 & .016 & 1.841 & $.040^{*}$ & -.008 to 0.062 \\
\hline
\end{tabular}

Co; coefficient, St Er; standard error; CI; confidence interval *P is significant at $5 \%$ level of significance

\section{DISCUSSION}

Although the shock absorbability of resilient liners has been well documented ${ }^{28,29}$, surprisingly, few clinical reports were concerned with evaluating the effect of resilient liners on mandibular bone resorption ${ }^{22,23}$ under conventional dentures, and there is no published studies on the effect of relining the mandibular overdentures with resilient liner on bone loss of mandibular jaw come to our knowledge.

The use of silicone based resilient liners was favored in this study than acrylic resin liners as dynamic viscoelastic properties of the siliconebased relining material were not affected by aging. In contrast, plasticized acrylic resins showed greater permanent deformation and they are gradually hardened as a result of continued polymerization and/or plasticizer loss which cause a reduced cushioning effect resulting in the transportation of higher occlusal force to the underlying mucosa. Also, the recovery of silicone material was better than of acrylic one ${ }^{30,31}$

Proportional area measurement in terms of area indices was advocated in several studies ${ }^{5,6,26,27,32,33}$ which deal with evaluation of posterior mandibular bone resorption using rotational tomographs as it reduces the problems associated with magnification. To eliminate the effect of magnification and distortion and to provide more accurate and reliable measurements, Cone Beam computerized tomography was used in this study instead of panoramic radiography. Moreover, a modification of this technique introduced by Tuebinger ${ }^{6}$ was used to reduce the inclusion of more anatomical structures that may be not clearly defined, but use implant structures instead which is more clearly defined, thus improving the accuracy of the technique. 
In both groups, PAI was more than .04 which was previously determined as the limit value of bone $\operatorname{loss}^{3,26}$. This means that bone resorption occurs in both groups. This may be attributed to the fact that overdentures are supported by mucosa in unrelined and relined groups

By comparing both groups, the mean posterior area index (PAI) of unrelined overdentures was statistically significant higher than the PAI of relined overdentures after 5 years of overdenture insertion. Also, the unrelined group was associated with increase in PAI by $10.6 \%$ per each year compared to relined group. This may be due to overdentures with clip attachments tend to rotate around the bar during mastication which may increase occlusal force on the posterior mandibular ridges ${ }^{3,9}$. Moreover, the increased modulus of elasticity of acrylic resin denture bases than that of supporting mucosa leading to areas of force concentration which result in tissue trauma and sore spots. The occlusal trauma could interfere with blood circulation in the mucosa and reduce oxygen tension which may activate osteoclast activity leading to alveolar bone loss 5 . In line with our finding Jacobs and associates ${ }^{3}$ reported higher posterior bone resorption for overdenture supported by two implants and connected by a bar (resilient joint), even though they had much shorter observation period ( 2 years) than the present study.

In contrary, the relined overdentures tended to settle totally towards mucosa rather than rotate around the bar thus distributing the occlusal force to the entire ridge and did not concentrate these forces on the posterior mandibular ridge areas. Moreover, resilient liners were found to reduce the impact force when compared to acrylic denture base resin ${ }^{29}$, it also act as a shock absorber (stress regulator), eliminate the local concentrations of stress on the mucosa, distribute stresses and eliminate sore spots under the denture due to its viscoelastic property ${ }^{28,29}$. Resilient liners provide intimate adaptation and optimal fit of the denture base to the posterior edentulous ridge which contribute to an even distribution of forces onto the implants and the residual ridges ${ }^{13}$, minimize localized crestal loading and negative remodeling of the underlying bone ${ }^{5}$. In agreement with this finding, Wright $^{34}$ reported that; ridge resorption was small in patients wearing mandibular complete denture relined with resilient liner.

The increase in mandibular bone height by one millimeter was associated with $1.5 \%$ reduction in PAI per year. This increase can be explained by when the ridge is well developed it is composed of alveolar (cancellous) and basal (compact) bone. Therefore, increasing occlusal load on alveolar bone causes the bone to be more liable to resorption. On the other hand, the bone height in reduced ridges is composed mainly of compact dense bone which is less liable to resorption so when the denture comes to rest mostly on basal mandibular bone, the rate of bone resorption reduces ${ }^{2,33}$. A similar finding was also noted in a another study ${ }^{6}$. Due to increased bone loss in patients with well-developed ridges, the use of implant overdentures in young patients should be cautious as it may increase the rate of mandibular ridge resorption ${ }^{6}$.

In contrast, other authors..$^{27}$ found no relation between mandibular bone height and ridge resorption. For each relining time, a reduction in the PAI by $3.2 \%(\mathrm{P}=.040)$ was observed. The relation between posterior ridge resorption and relining times agreed with several investigations $\mathrm{s}^{14,35}$ and could be attributed to the reduced stability and retention and the misfit of the overdentures caused by ridge resorption.

Overall, the null hypothesis was rejected. However, the limitations of this study included the small patient sample and the short period of observation. A large patient cohort is needed with longer follow up period to ensure the finding of the present study on the long term. Another suggestion of future research is to study the prosthetic complications and maintenance of relined dentures after a long period of denture use. This study also signifies the importance of studying stress transmission characteristics in posterior mandibular bone of implant retained overdenture and its association with radiographical tissue changes 


\section{CONCLUSION}

Within the limitations of this study, it could be concluded that relined implant retained mandibular overdentures with silicon soft liner over bar attachments is preferred on long term as it reduced posterior mandibular ridge resorption compared to unrelined overdentures

\section{REFERENCES}

1. Feine JS, Carlsson GE, Awad MA, Chehade A, Duncan WJ, Gizani S, Head T, Heydecke G, Lund JP, MacEntee M, Mericske-Stern R, Mojon P, Morais JA, Naert I, Payne AG, Penrod J, Stoker GT, Tawse-Smith A, Taylor TD, Thomason JM, Thomson WM, Wismeijer D. The McGill consensus statement on overdentures. Mandibular twoimplant overdentures as first choice standard of care for edentulous patients. Gerodontology 2002; 19: 3-4.

2. Wright PS, Glantz PO, Randow K, Watson RM. The effects of fixed and removable implant-stabilised prostheses on posterior mandibular residual ridge resorption. Clin Oral Implants Res 2002; 13: 169-174.

3. Jacobs R, Schotte A, van Steenberghe D, Quirynen M, Naert I. Posterior jaw bone resorption in osseointegrated implantsupported overdentures. Clin Oral Implants Res 1992; 3:63-70.

4. Heckmann SM, Schrott A, Graef F, Wichmann MG, Weber HP. Mandibular two-implant telescopic overdentures. Clin Oral Implants Res 2004; 15: 560-569.

5. Elsyad MA, Mohamed SS, Shawky AF. Posterior Mandibular Ridge Resorption Associated with Different Retentive Systems for Overdentures: A 7-Year Retrospective Preliminary Study. Int J Prosthodont 2017; 30: 260-265.

6. Raedel M, Lazarek-Scholz K, Marre B, Boening KW, Walter $\mathrm{MH}$. Posterior alveolar ridge resorption in bar-retained mandibular overdentures: 10-year results of a prospective clinical trial. Clin Oral Implants Res 2015; 26: 1397-1401.

7. Carpentieri JR. Clinical protocol for an overdenture bar prosthesis fabricated with $\mathrm{CAD} / \mathrm{CAM}$ technology. Pract Proced Aesthet Dent 2004; 16: 755-757.

8. Kurtzman GM. The locator attachment: free-standing versus bar-overdentures. Dental Labor International Plus 2009:20-23.

9. Heckmann SM, Winter W, Meyer M, Weber HP, Wichmann MG. Overdenture attachment selection and the loading of implant and denture-bearing area. Part 2: A methodical study using five types of attachment. Clin Oral Implants Res 2001; 12: 640-647.

10. Elkerdawy MW, Radi IA. Effect of dislodging forces on mandibular implant attachment-retained overdenture. Implant Dent 2011; 20: 246-254.

11. Naert IE, Hooghe M, Quirynen M, van Steenberghe D. The reliability of implant-retained hinging overdentures for the fully edentulous mandible. An up to 9-year longitudinal study. Clin Oral Investig 1997; 1: 119-124.

12. Tymstra N, Raghoebar GM, Vissink A, Meijer HJ. Maxillary anterior and mandibular posterior residual ridge resorption in patients wearing a mandibular implant-retained overdenture. J Oral Rehabil 2011; 38: 509-516.

13. ELsyad MA. Prosthetic aspects and patient satisfaction with resilient liner and clip attachments for bar- and implant-retained mandibular overdentures: a 3-year randomized clinical study. Int J Prosthodont 2012; 25: 148-156.

14. Elsyad MA, Ashmawy TM, Faramawy AG. The influence of resilient liner and clip attachments for bar-implantretained mandibular overdentures on opposing maxillary ridge. A 5-year randomised clinical trial. J Oral Rehabil 2014; 41: 69-77.

15. ELsyad MA, Mohamed SS, Shawky AF. Posterior mandibular ridge resorption with resilient liner and clip attachments of bar/implant retained overdentures. A 7-year retrospective radiographic study. Int J Prosthodont 2017 May/ June;30(3):260-265.

16. Elsyad MA, Shoukouki AH. Resilient liner vs. clip attachment effect on peri-implant tissues of bar-implant-retained mandibular overdenture: a 1-year clinical and radiographical study. Clin Oral Implants Res 2010; 21: 473-480.

17. Elsyad MA. Soft liner/clip attachment for bar retained implant overdentures. A technical note. J Oral Implantol 2016; 42: 442-445.

18. Adrian ED, Krantz WA, Ivanhoe JR. The use of processed silicone to retain the implant-supported tissue-borne overdenture. J Prosthet Dent 1992; 67: 219-222.

19. Kiat-Amnuay S, Khan Z, Gettleman L. Overdenture retention of four resilient liners over an implant bar. J Prosthet Dent 1999; 81: 568-573.

20. ELsyad MA, Shaheen NH, Ashmawy TM. Long-term clinical and prosthetic outcomes of soft liner and clip attachments for bar/implant overdentures: a randomised controlled clinical trial. J Oral Rehabil 2017; 44: 472-480. 
21. elCharkawi HG, elMahdy AS. The effect of resilient layer and occlusal reactive complete dentures on the residual alveolar ridge. J Prosthet Dent 1988; 59: 598-602.

22. Reddy KK, Prasanna RG, Sundaresh KJ, Mallikarjuna R. Reactive dentures: a novel approach to decrease residual ridge resorption. BMJ Case Rep 2013; 2013.

23. Babu BD, Jain V, Pruthi G, Mangtani N, Pillai RS. Effect of denture soft liner on mandibular ridge resorption in complete denture wearers after 6 and 12 months of denture insertion: A prospective randomized clinical study. J Indian Prosthodont Soc 2017; 17: 233-238.

24. Ahuja S, Cagna DR. Defining available restorative space for implant overdentures. J Prosthet Dent 2010; 104: 133-136.

25. Wright PS. Soft lining materials: their status and prospects. J Dent 1976; 4: 247-256.

26. Wilding RJ, Levin I, Pepper R. The use of panoramic radiographs to measure alveolar bone areas. J Oral Rehabil 1987; 14: 557-567.

27. Kordatzis K, Wright PS, Meijer HJ. Posterior mandibular residual ridge resorption in patients with conventional dentures and implant overdentures. Int J Oral Maxillofac Implants 2003; 18: 447-452.

28. Kawano F, Ohguri T, Koran IA, Matsumoto N, Ichikawa $\mathrm{T}$. Influence of lining design of three processed soft denture liners on cushioning effect. J Oral Rehabil 1999; 26: 962-968.
29. Kawano F, Koran A, Nuryanti A, Inoue S. Impact absorption of four processed soft denture liners as influenced by accelerated aging. Int J Prosthodont 1997; 10: 55-60.

30. Salloum AM. Creep and stress relaxation behavior of two soft denture liners. J Indian Prosthodont Soc 2014; 14: 93-97.

31. Santawisuk W, Kanchanavasita W, Sirisinha C, Harnirattisai C. Dynamic viscoelastic properties of experimental silicone soft lining materials. Dent Mater J 2010; 29: 454-460.

32. de Jong MH, Wright PS, Meijer HJ, Tymstra N. Posterior mandibular residual ridge resorption in patients with overdentures supported by two or four endosseous implants in a 10-year prospective comparative study. Int J Oral Maxillofac Implants 2010; 25: 1168-1174.

33. Wright PS, Watson RM. Effect of prefabricated bar design with implant-stabilized prostheses on ridge resorption: a clinical report. Int J Oral Maxillofac Implants 1998; 13: $77-81$.

34. Wright PS. Observations on long-term use of a soft-lining material for mandibular complete dentures. J Prosthet Dent 1994; 72: 385-392.

35. Watson GK, Payne AG, Purton DG, Thomson WM. Mandibular overdentures: comparative evaluation of prosthodontic maintenance of three different implant systems during the first year of service. Int J Prosthodont 2002; 15: 259-266. 